METHANOL, NATURAL GAS, AND THE DEVELOPMENT OF ALTERNATIVE TRANSPORTATION FUELS

Melvin L. Kliman

Department of Economics, McMaster University, Hamilton, Ontario, Canada L8S 4M4

RR-84-10

May 1984

Reprinted from Energy, volume 8 (1983)

INTERNATIONAL INSTITUTE FOR APPLIED SYSTEMS ANALYSIS

Laxenburg, Austria 
Research Reports, which record research conducted at IIASA, are independently reviewed before publication. However, the views and opinions they express are not necessarily those of the Institute or the National Member Organizations that support it.

Reprinted with permission from Energy 8(11):859-870 (1983)

Copyright @ 1983 Pergamon Press Ltd.

All rights reserved. No part of this publication may be reproduced or transmitted in any form or by any means, electronic or mechanical, including photocopy, recording, or any information storage or retrieval system, without permission in writing from the copyright holder.

Printed by Novographic, Vienna, Austria 


\section{FOREWORD}

The demand for liquid fuels for end use is expected to persist over the next few decades and to outstrip the supply capability of conventional oil resources. Synthetic liquid fuels will play a major role in meeting this demand. This is a major finding of the IIASA global energy analysis Energy in a Finite World and of the recent IIASA '83 Scenario of Energy Development to the year 2030.

From a resource standpoint both coal and gas can be used for the production of synfuels. However, recent technological advances in deep drilling and in transporting gas over long distances point to the enhanced availability of gas resources and the technical feasibility of expanded use of gas. Among the various gas-based synfuels, methanol has the greatest potential as an alternative fuel, particularly in the transport sector. Dr. Kliman's work at IIASA offers valuable insights into the current state of the methanol industry and the prospects worldwide of methanol fuel development based on natural gas.

HANS-HOLGER ROGNER

Leader

IIASA International Gas Study 



\title{
METHANOL, NATURAL GAS, AND THE DEVELOPMENT OF ALTERNATIVE TRANSPORTATION FUELS $\dagger$
}

\author{
Melvin L. Kliman \\ Department of Economics, McMaster University, Hamilton, Ontario, Canada L8S 4M4
}

(Received 14 December 1982)

\begin{abstract}
The potential for methanol as a motor fuel, particularly when it is produced from natural gas, is examined. Diverse information related to methanol fuel development is gathered together and the process by which such a new fuel market would evolve is considered. It is concluded that methanol has the capacity to be a significant alternative fuel, but that the realization of that capacity is not yet imminent.
\end{abstract}

\section{INTRODUCTION}

Despite recent declines in oil prices, the development of alternative fuels remains a matter of great interest. The goal of diversifying fuel use will continue to be pursued in most countries because the oil supply situation is viewed as highly dependent upon the current recession and subject to rapid change. Here we examine the prospects for methanol, with particular emphasis on its production from natural gas.

\section{ALCOHOLS AS MOTOR FUELS}

Alcohols are attractive as alternatives to oil-based fuels because they are potentially abundant, flexible in both production and use, and relatively more compatible with the existing fuels system than other alternatives. ${ }^{1-5}$ Other choices, such as liquefied natural gas (LNG), compressed natural gas, liquefied petroleum gas and hydrogen are lacking in one or more of these attributes and do not now have the potential for a large impact on fuel supply in the way that alcohols do.

The two alcohols most appropriate for use as fuels, methanol and ethanol, can be produced from a variety of feedstocks. Most current production of methanol is from natural gas, but in a scenario for alternative fuels, coal, wood and heavy crude oils are also relevant sources. As an alternative fuel, ethanol is produced by the fermentation of biomass.

This flexibility suggests some obvious scenarios for the development of alcohol fuels. If one views natural gas as the initial source, with coal and renewable feedstocks to be phased in slowly when relative price changes make them more efficient, alcohol fuels would be sustainable into the indefinite future. A variation on this scenario would recognize the desire in many countries to reduce their dependence on imported energy. If such countries do not have gas reserves, biomass or domestic coal could be phased in more quickly.

A key advantage of alcohols is that they can be used either as a separate fuel or in a blend with gasoline. In low ratio blends, they can be burned in vehicles designed for gasoline with little or no change. The maximum ratio that can be used without vehicle conversion is not widely agreed upon, but appears to be in the $5-10 \%$ range. It is influenced by local conditions (e.g., climate) and by the performance standards demanded.

Focusing specifically on methanol, a number of advantages and disadvantages will play a role in its prospects for adoption. Blended with gasoline it increases octane levels, reduces automotive air pollutants (except for aldehydes) and is a deicer. On the other hand, methanol separates from gasoline under water contamination, can cause vapor lock (an interruption in the fuel flow) and in high concentrations will corrode some materials now used in vehicle fuel systems. Larger fuel tanks are necessary for pure methanol or high ratio

†This paper was written while the author was at the International Institute for Applied Systems Analysis, Laxenburg, Austria. The work was supported by funds from the program for International Cooperation in Systems Analysis Research, administered by the U.S. National Academy of Sciences. 
blends because it contains less energy per unit volume. Its lower energy content is partially offset, however, for methanol burns more efficiently than gasoline in vehicle engines. Some argue that in low ratio blends it can replace gasoline on a $1: 1$ basis by volume without significant power loss.

Some of the difficulties associated with methanol are easily overcome, while others are more serious obstacles. Since this is not meant to be a comprehensive technical account, no definitive position on technological obstacles is attempted. It is sufficient to observe that a great deal of research and development is underway and that there is no suggestion in the literature that the problems are insurmountable. $\dagger$

NATURAL GAS AND METHANOL IN A TRANSFORMED FUELS SYSTEM

A number of observations will help to provide some background for the discussion.

(1) In comparison with oil, the average distance over which natural gas has been transported has historically been short. Gas is expensive to transport. This distance has been growing rapidly, however, as gas reserves more remote from major markets are now being exploited. This is important in the present context, for methanol could be an efficient carrier of natural gas energy over long distances, especially where bodies of water must be traversed. Currently this is done by under-sea pipelines for short distances and by LNG over long distances. LNG is relatively cheap to produce in energy terms, but is expensive to transport and store at the receiving end. More energy is used up in producing methanol, but it can be transported cheaply in ordinary tankers. $\neq$ Thus, there are some combinations of natural gas prices and transportation distances for which methanol is the cheaper carrier.

(2) In relative terms, the use of methanol as a fuel would not require a major modification of the overall fuels system. A methanol industry already exists; the use of alcohol as motor fuel has been understood and applied for a long time; and the option of mixing it with gasoline simplifies its introduction. In absolute terms, however, the required long-term adjustment would still be large. Private investment in a methanol fuels industry is subject to a threshold of preparation by both government and industry that must be crossed before entrepreneurs will be willing to make commitments. Many production and service activities must be underway simultaneously to make large-scale investment profitable. The literature contains numerous claims that action is difficult because of a "chicken-egg problem" between the availability of alternative fuels and the motor vehicles that can use them.

(3) The use of natural gas to produce large amounts of fuel methanol must compete with the direct consumption of natural gas for space heating, water heating and other conventional uses.

(4) The competition between methanol and the currently used motor fuels, the competition between methanol and LNG as carriers of natural gas energy from remote reserves, and the competition between the conventional uses of natural gas and its use to produce fuel methanol are all fought on unequal ground. New products typically suffer a disadvantage if they must compete with well-established products, especially in industries subject to scale economies and large sunken costs.

(5) Observations (2) and (4) indicate that there is a role for government in the development of alcohol fuels. As alcohol fuel markets take shape one can expect positive spillover effects to occur. These effects, which can be expected to reduce costs, will not be taken into account by private investors in the normal course of their decisions. If governments do not finance them they will be underproduced. Thus it is efficient for governments to aid in the coordination of investment decisions, provide research services, subsidies and other manner of support that would help to offset the competitive disadvantages to which new fuels are subject. This assumes, of course, that alcohol fuels will be competitive once they have a share of the market or, if not, that the community for whom governments are acting is willing to pay something to have alternative fuels available even if they are more expensive than those currently used.

†This is true in regard to spark-ignition engines. Work is also being done on the use of methanol in diesel engines. In this case, the problems are greater.

†Estimates of the energy losses in production vary. A textbook on natural gas sets these at $25 \%$ for $\mathrm{LNG}$ and $40 \%$ for methanol, ${ }^{6}$ although much lower losses are quoted in other contexts. 
In light of the above observations, the following topics are examined in the remainder of this paper: governmental programs in aid of the use of alcohol fuels, trends in the existing methanol industry, activities that relate to the long-distance transport of natural gas and methanol, and the supply-demand situation in the conventional natural gas industry.

\section{NATIONAL PROGRAMS AS AGENTS OF CHANGE}

Government programs for research and development of alcohol fuels are underway in numerous countries. Much of the activity in the private sector can be linked to these programs, which are usually part of broader efforts to develop alternative fuels. A number of elements appear frequently: the testing of both blends and pure alcohols in actual use, in some cases on a large scale; the search for alcohol-gasoline mixes most suitable for local conditions; attempts to use locally produced feedstocks; attempts to deal with the phase separation problem and with cold weather starting; and the development of automotive equipment specifically designed for alcohol-fueled vehicles. In some countries there are plans, more or less tentative, to introduce or expand the use of alcohols on a commercial scale according to a projected timetable. A full survey of national programs is not attempted here. To illustrate the extent to which fuel methanol has developed, however, three programs are briefly described.

\section{New Zealand}

The New Zealand program is highly conditioned by local characteristics: a small economy, without its own auto industry, an automobile population that is diverse and turns over slowly, a precarious balance of payments, and domestic reserves of natural gas (but not oil). It is a natural place for the first commercial application of the Mobil Oil technique of producing gasoline from natural gas via methanol. Two plants will produce 2200 (metric) $\mathrm{t} /$ day of methanol each. This will be converted into $570,000 \mathrm{t} / \mathrm{year}$ of gasoline at an estimated cost of NZ\$490/t (Ref. 4, Vol. 3, pp. 246 47), which works out to roughly $\$ 0.29 / 1$, based on the exchange rate in the first quarter of $1982 . \dagger$ Just over half of the venture is owned by the New Zealand Synthetic Fuels Corporation; Mobil Oil, with a one-quarter interest will manage it; the rest belongs to BP, Shell and Caltex. ${ }^{7}$ It is expected eventually to provide about $30 \%$ of New Zealand's gasoline consumption (Ref. 4, Vol. 3, p. 316).

A separate methanol plant with a capacity of $396,000 \mathrm{t} /$ year is also to be built. Though the use of methanol-gasoline blends is considered to be uneconomic at present, the possibility of using some of the output of the new plant for that purpose is a part of the New Zealand strategy. Moreover, research into the use of high-ratio blends or nearly pure alcohol is underway (A. L. Titchener in Ref. 4, Vol. 3, p. 399). The government also provides incentives for the use of compressed natural gas. If its target is met, $10 \%$ of road vehicles will run on CNG by the end of 1985 . The overall program (which has not been exhaustively described here) is expected to reduce New Zealand's transport fuel imports from their present level of $90 \%$ of total consumption to $50 \%$ by the mid 1980 's.

While the New Zealand program has inevitably suffered some difficulties (J. P. West in Ref. 4, Vol. 3, p. 417), it is impressive, and of some importance as a bellwether for other countries. The need for action is greater in New Zealand than in most other high income countries and, because it is a small and isolated country with a centralized government, it has greater scope for independent action. It may provide some indication of what will be done in countries where change is taking place more slowly. Certainly other countries will benefit from knowing of its experience with the Mobil process.

\section{California}

Alcohol fuels are already used in low ratio blends in the U.S. While the aggregate amount consumed is small, about 10,000 service stations are selling blends of gasoline and

†Dollar figures refer to U.S. dollars unless otherwise indicated. Conversions have been made with average exchange rates published in the IMF's International Financial Statistics. 
ethanol (Ref. 4, Vol. 3, p. 336). Ethanol may have some potential in the long run, but it is a curious choice for the U.S. at this stage and is likely to give way to methanol. The latter is, for instance, the preferred choice of the designers of an aggressive program in California (K. O. Smith, A. C. Edwards, M. C. McCormick, and D. S. Kondolem in Ref. 4, Vol. 3, p. 369). California's vehicle population is very high and is likely to continue growing. Minor deficiencies in fuel supply, of only $3-5 \%$, caused great difficulties during the shortages that occurred in the 1970's. Alternative fuels offer some opportunities to overcome such shortages, as well as to combat California's uniquely serious air pollution problem.

The California program is intended to encourage the use of alcohol-gasoline blends in the near term and of pure alcohols in the long term, to bring about supply increases, and to develop new uses of alcohol fuels. The effort is broadly based because "to be effective, alternative fuels must possess the capability to displace the majority of refined products from crude oil" (Ref. 4, Vol. 3, p. 372). If only gasoline were to be displaced, the need for related products would continue to support the demand for petroleum refining. Since there is limited flexibility in breaking down crude oil, local gasoline surpluses could emerge, which would undercut the market for methanol. To this end, work on the use of methanol in diesel engines and in large stationary utility and industrial engines is underway. For automotive use, low-ratio blends are to be de-emphasized in the long term. They are thought to be a less efficient way to use alcohol and to have adverse effects on air quality relative to the use of neat alcohols.

The flow of methanol from existing California plants using piped natural gas is expected to meet fuel needs through 1987. Production at the sites of remote natural gas reserves is then likely to become important, eventually giving way to coal gasification. California's large supplies of heavy crude oil may lead to its use as a feedstock as well.

\section{France}

The French alcohol fuels program was begun in early 1981 and consists of two stages. $\dagger^{8,9}$ The first, expected to run through 1985, involves the gradual introduction of alcohol-gasoline blends up to a maximum of $10 \%$. It is assumed that this can be done without changes in vehicles or in retail fuel distribution. A large research and testing program is underway. The second stage (1986-90) assumes that vehicles and the distribution system will be modified as higher ratio blends are introduced. At some point, the motorist is envisioned as having a choice between gasoline (perhaps containing a low ratio of alcohol) and a fuel with a high alcohol content.

The major objective is to develop a workable fuel that can be produced from domestically available feedstocks. Coal and various crops, some of which can be grown on marginal land, are the desired sources. The possibility of using natural gas is acknowledged (as is its current cost efficiency relative to other feedstocks) $\ddagger$ but it does not appear to form an integral part of the final goals of the plan. Nevertheless, it is likely to play an interim role in providing methanol, until other sources become cost effective and available in sufficient amount. What will surely be important in the timing of this is the supply-demand balance in the conventional gas sector. France is currently expanding and diversifying its gas supplies, though whether or not any of the expanded supply is foreseen as a backup feedstock for liquid fuel is not known.

The French program is likely to be important in the European context if the projected schedule is maintained. It will provide a nearby demonstration for other European countries that have not yet made a commitment to change. With its large auto industry, it could also be important in initiating changes in vehicle design.§ Leadership and

†Some of the following information was obtained by interviews with researchers at the Institut Français du Pétrole (IFP).

†For example, data provided by IFP in early 1982 indicate that methanol can be produced from natural gas at $1400 \mathrm{francs} / \mathrm{t}$ (assuming a gas price of $\$ 5-5.50 / 10^{6} \mathrm{Btu}$ and a plant capacity of $600,000 \mathrm{t} / \mathrm{yr}$ ), and from coal at 1800 francs/t (assuming a coal price of 400 francs/t).

IIn this regard, the extensive program of vehicle testing and development in the FRG should also be noted (H. Meckel and R. Paulsen, Ref. 4, Vol. 3, p. 41). 
coordination is important in Europe, where the large amount of cross-country vehicle traffic requires some level of harmonization in alternative fuels programs.

\section{THE EXISTING METHANOL INDUSTRY}

\section{Methanol prices}

Prices in the existing methanol industry provide some indication of what methanol fuel could sell for. Though methanol for chemical uses is refined to a greater purity, the same processes would apply. Unfortunately, well-organized price data on methanol are not available. Based on the rough quotations that were found, it appears that methanol can be produced more cheaply than gasoline per unit volume in many countries. Estimates for France, West Germany and the U.S. that apply to late 1981 or early 1982 all work out to about $\$ 0.19 / 1 . \dagger$ Average pre-tax prices for gasoline in the first quarter of 1981 in these three countries were $\$ 0.38 / 1, \$ 0.31 / 1$, and $\$ 0.35 / 1$ respectively. ${ }^{10}$

These comparisons indicate that methanol is now a viable fuel if it is used to replace gasoline in low-ratio blends where it can be substituted on a 1:1 basis. If pure methanol or high-ratio blends are to be attractive the prices must be adjusted to account for methanol's lower energy content. Since the vehicle technology for this is not yet known, the factor that should be applied to construct a comparable price is not available. If, for example, the price must be increased by $30-40 \%$, methanol would no longer look so competitive at current gasoline prices. The likelihood that methanol-compatible vehicles will, at least initially, be more expensive than existing ones adds to the market barriers.

Thus, market penetration beyond the range of $5-10 \%$ of gasoline consumption is not to be expected unless one or more of the following contingencies occur. (a) Oil shortages or other market phenomena could cause gasoline prices to rise more than methanol prices. (b) In the manner typical of new industries, the real price of methanol could fall due to cost decreases that occur as the methanol fuels industry grows. (c) Governments could choose to tax methanol at a lower rate per energy unit than gasoline in order to offset its initial competitive disadvantage or, even in the long term, in order to finance the resource cost of a more secure energy supply that comes with using a larger variety of fuels. Governments are searching not merely for a cost-efficient substitute for oil but one that can be produced domestically.

\section{Production forecasts}

World production of methanol in 1980 is estimated to be 13 million tons. It has been growing rapidly, at about $8 \%$ per annum from 1974 to 1980 . Industry forecasts and a survey of construction underway and planned ${ }^{11}$ indicate that growth in the range of $5-10 \%$ per annum will continue. Forecasts of annual capacity for 1990 fall into the range of 23-24 million tons. Excess demand is expected to continue until the mid-1980's after which surplus supplies are expected. ${ }^{12-14}$ Some of the new capacity is being built in the Middle East in an attempt to use associated gas that is not flared (in 1979, 44\% of the natural gas produced in OPEC countries was flared). ${ }^{15}$

Detailed information on end uses and product prices associated with existing and new capacity is not available. While small amounts of methanol are mixed with gasoline by a few scattered refiners, the proportion of total world output currently used for fuel is negligible. Some of it does appear in fuel by another route, as additives, such as methyl tertiary butyl ether, an octane booster for unleaded gasoline. This use is expected to grow. Methanol is mainly used to produce formaldehyde and other chemicals, as an industrial solvent, and as a denaturant. In the United States, in 1979, only $1 \%$ of methanol consumption was in the form of fuel. Forecasters have, however, begun to view fuel consumption as a significant component of methanol demand (at least as indicated by forecasts made before recent declines in oil prices). For instance, a privately circulated forecast from E.I. Dupont predicts that by $198520 \%$ of U.S. methanol demand will be for fuel consumption, with half of that consumed directly and the rest in the form of MTBE.

†The French estimate is based on a natural gas price of $\$ 5 / 10^{6} \mathrm{Btu}$. The West German and U.S. estimates are found in Ref. 4, Vol. 1, pp. 16 and 112. 
While indications that the methanol industry is beginning to turn its attention to the fuel market are important, the signs of such attention are still weak. Except for the New Zealand project and a small pilot plant in FRG designed to test an alternative version of the Mobil process, ${ }^{11,16}$ evidence of market development was not encountered. Though it is possible that methanol producers are simply unwilling to announce their plans, the absence of overt preparation by suppliers means that development is not imminent.

A real commitment to methanol as a fuel would effectively require the building of a new industry. One source estimates the current surplus of methanol over the demand for it in chemical use as less than $1 \%$ of world gasoline demand (Ref. 4, Vol. 3, p. 228). To have some idea of the magnitude involved, consider current gasoline consumption in OECD countries and the possibility of a $10 \%$ methanol-gasoline blend. The existing world methanol industry, if it were totally devoted to fuel production, would be able to supply only about one-quarter of the methanol required. At the same time, there is a great deal of natural gas potentially available to produce methanol. For instance, two plants being built in Saudi Arabia, with a total capacity of about $4000 \mathrm{t} / \mathrm{day},{ }^{11}$ will require less than $3 \%$ of the gas flared in that country in 1979. If one considered using all of Saudi Arabia's flared gas for this purpose (obviously only as a rough illustration, since it could be uneconomic to do so), the result would be equivalent to more than three times the current world methanol supply. $\dagger$

\section{ALTERNATIVE METHODS OF TRANSPORTING NATURAL GAS ENERGY}

If, as in Saudi Arabia, developers of remote gas reserves increasingly choose to produce methanol, rather than to flare the gas or to export it by pipeline or LNG, the effect on methanol supplies would help to stimulate its use as a fuel. To explore this possibility, one needs to compare the profitability of alternative methods of exploiting given stocks of natural gas. A few studies of this sort are available, though they are somewhat limited in scope.

\section{Natural gas net-back values}

An Italian firm that builds natural gas infrastructure has prepared a study that compares ways of exporting gas from the Middle East and Africa to Europe. ${ }^{18,19}$ They compute net-back values for natural gas in different uses: starting from assumed European prices for gas and converted products they deduct capital costs, transport costs, conversion energy losses, and other charges to arrive at the amount left per unit of gas at the export point. The European price for methanol is assumed to be $\$ 180 / \mathrm{t}$, which is approximately $\$ 0.14 / 1$. This places the methanol price roughly in the range that will just compete with gasoline if the difference in energy content is accounted for. Thus, the authors have not accounted for the more favourable possibility of 1:1 substitution in low-ratio blends. The market for fuel use is assumed to be $1.5 \times 10^{6} \mathrm{t} / \mathrm{yr}$, requiring $15-20$ plants each with a capacity of as much as $5000 \mathrm{t} /$ day. This would generate a net-back revenue of $\$ 2.50-2.70 / 10^{6}$ Btu (1980 dollars). This value is higher than they obtain for all the other products converted from methane.

The assumed distance over which the methanol is to be transported has not been reported, but it appears that a single average distance has been used. Since the marginal cost per kilometer is low, the use of an average site may not affect the results materially. This is not so in the case of LNG or pipelines, and the authors do various comparisons over distances ranging from 3500 to $11,300 \mathrm{~km}$. Assuming a natural gas value (as of April 1980 ) at the inlet of the European gas system of $\$ 4.10 / 10^{6}$ Btu, they obtain net-back values for gas carried by pipeline and ship, all of which are lower than the netback value of methanol. Thus, of all the alternatives considered that involve the use of large volumes of gas, methanol has the highest netback value (Ref. 19, Fig. 24). The only ones that are still higher are ethylene, which is produced from ethane, a small component of gas, and

†In 1979, 37,990 $\times 10^{6} \mathrm{~m}^{3}$ of gas were flared in Saudi Arabia. A typical plant using the ICI process requires $2.3 \times 10^{6} \mathrm{kcal}$ of gas per ton of methanol. ${ }^{17}$ For purposes of this illustration, a cubic meter of gas is assumed to contain $8905 \mathrm{kcal}$. 
the use of gas as refinery fuel; the latter is assumed to have a market $17 \%$ the size of the fuel methanol market, which was itself conservatively estimated.

Despite these results, the authors apparently view methanol fuel as something that will utilize only limited quantities of natural gas in the producing countries considered. On the other hand, they perceive a wide market in Western Europe for the conventional use of gas. The authors of a study of natural gas published by the International Energy Agency $(\text { IEA })^{20}$ consider the results of the Italian study, expand upon their analysis, and come to similar conclusions. The conservative nature of these conclusions suggests that initiatives from the gas industry in the development of a methanol fuel market are not yet to be expected.

\section{Transport cost comparison}

Another methanol-LNG comparison, based on 1973 data, involves comparisons of the costs of delivering $165 \times 10^{12} \mathrm{Btu} / \mathrm{yr}$ of gas into an importing country pipeline system, either by way of LNG carriers or by methanol carried in ships and used to produce substitute natural gas. ${ }^{21}$ The analysis indicates that the costs of gas delivery vary with the price of natural gas at the well and that, as distance increases, the cost of transporting LNG rises more rapidly than the cost of transporting methanol. For the two routes considered (from the Persian Gulf to the U.S. and Japan), methanol is the cheaper method.

Figure 1 illustrates the effects of both transport distance and the price of natural gas on delivery cost. At low prices for the gas input, the higher capital costs of LNG lead to a higher delivered cost per unit. But, because of greater energy losses in production, methanol is more sensitive to higher prices for natural gas. Thus, the methanol relation has a higher gradient and can lose its advantage at a sufficiently high gas price. $†$ The curves

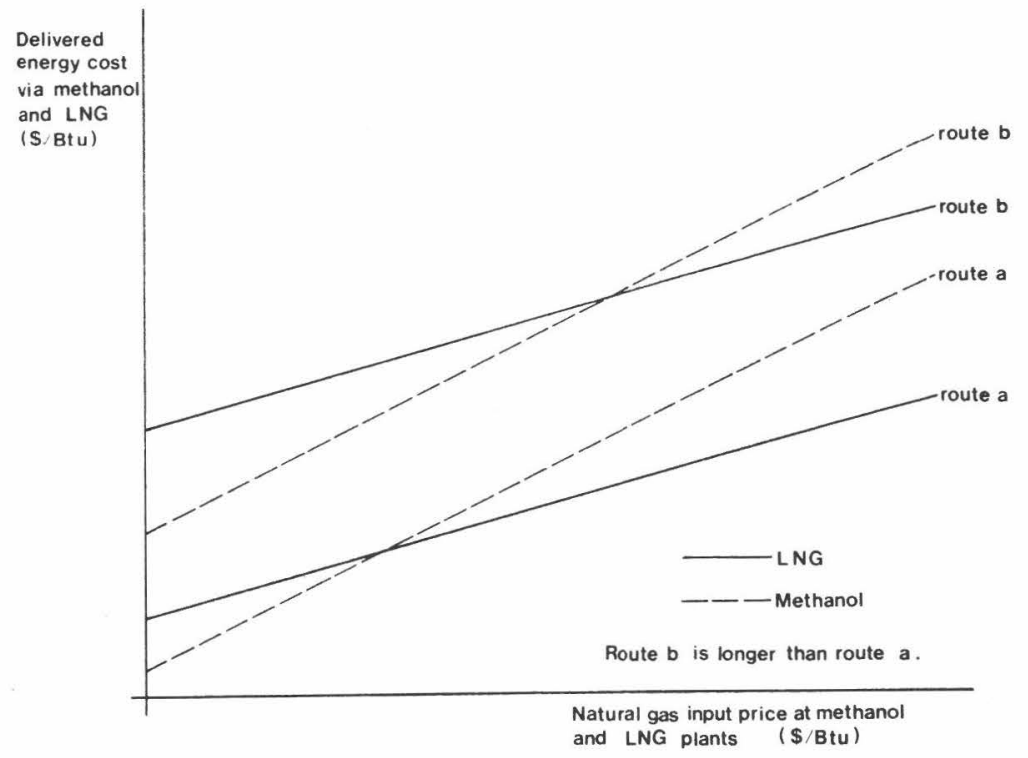

Fig. 1. Delivered natural gas cost as a function of transport distance and gas input price.

†Humphreys does not clarify his reasoning in regard to the relative slopes, but the difference in production losses must be the key factor. Let $A C_{i}=$ the cost per unit of energy delivered over a given distance by liquid fuel process $i, K_{i}=$ all costs per unit of output other than the cost of gas, $P=$ the price of gas to the liquid fuel producer, and $G_{i}=$ the gas required per unit of energy delivered via fuel process $i$, then $A C_{i}=K_{i}+P G_{i}$. Suppose that there is a $17 \%$ energy loss in delivering LNG to the gas system and a $35 \%$ loss in delivering methanol. Then $\delta A C_{M} / \delta P=1.28 \delta A C_{\mathrm{LNG}} / \delta P$. 
are higher for longer distances, but the LNG curve rises more per unit change in distance than does the methanol curve. The crossover point thus occurs at a higher natural gas price. The methanol advantage is more robust with respect to gas price increases the longer the route taken for delivery.

Given the expectation that natural gas prices are tied to oil prices, this analysis may help to explain why LNG has been the preferred method of trans-oceanic shipment, even over distances that appear to favour methanol.

\section{Feasibility studies}

Additional information on remote methanol production is provided by feasibility studies for particular projects, such as a proposal to produce methanol with associated gas from Alaskan oil fields for shipment to the lower 48 states. So far, the pipeline option has been favoured, but the project has not been finalized and some argue that it is unnecessarily expensive relative to the methanol option. In a recent version of the Alaskan plan proposed by Dubetz and Marsden, ${ }^{22,23}$ fuel-grade methanol would be produced in barge-mounted plants at Prudhoe Bay, the source of the gas. They claim that methanol can be delivered to the U.S. west coast from Alaska for about 16ф/1 (1981 values). At the time the market price for methanol was in the range of $18-24 \phi / 1$.

If all of the available Alaskan gas were to be converted to methanol, this approach would add massively to the total methanol supply. Up to 16 barge-mounted plants are envisaged, each with a capacity of $3000 \mathrm{t} /$ day. At 300 days per year, their potential production is $14.4 \times 10^{6} \mathrm{t} / \mathrm{yr}$, more than the current annual world production. With barge-mounted modules, however, production can be expanded incrementally without building capacity into the system until it is needed. This is an advantage over pipelines, which need to be large and operated close to full capacity to be efficient.

The same group is researching additional sites at which the barge-mounted methanol plants could be efficiently applied (S. S. Marsden, Jr. in Ref. 4, Vol. 1, p. 21). One possibility is to use them in offshore locations, thereby removing the need for field-to-shore pipelines. Their mobility could also be advantageous in the exploitation of small gas reservoirs. These and other features lead to the claim that this technology could also be economically applied off the northern coast of Australia, along coastal Nigeria, in the Guajira Peninsula, Colombia, in Indonesia, and in northern Canada. So far some of these sites have been examined only superficially and some in detail.

Others see it as desirable to go one step further and produce gasoline on site from the methanol. In Canada plans are developing to move some Arctic gas reserves in the form of LNG. A study published by Atomic Energy of Canada Limited ${ }^{24}$ suggests that the very high cost of transporting LNG under Arctic conditions could make methanol and gasoline production the preferred option. The authors claim... "that Arctic gasoline based on natural gas at less than $\mathrm{Cdn} \$ 2 / 10^{3} \mathrm{ft}^{3}$ (about U.S. $\$ 1.67 / 10^{6} \mathrm{Btu}$ ) would be competitive in the world gasoline market"' (p. 22). Though some Canadian gas is now sold at well-head prices within this range, the proposal is very speculative.

\section{METHANOL AND THE SUPPLY OF GAS}

It remains to consider whether, in a broad context, producing methanol for fuel is likely to be the best use of expanded natural gas production. Some evidence for a prima facie case that it is an efficient use of gas reserves has been cited in the preceding discussion, though it is not conclusive in regard to the basic question: for a given community, which application of natural gas will bring the highest incremental return? This is a national policy decision that will depend on supply and demand, prices and government actions. Detailed forecasts are not attempted here, but it is useful nonetheless to set out the key facts.

Natural gas reserves are large relative to current usage. $\dagger$ Definitions vary, but proven reserves are roughly evaluated at $40-50 \mathrm{yr}$ of gas consumption. Estimated total potential reserves place natural gas in the same order of magnitude as oil. Reserve estimates are being

†This is true in regard to conventional definitions of reserves. For information on unconventional possibilities see Ref. 25. 
revised upwards and this is likely to continue. The ratio of proven-to-potential reserves is low relative to that for oil. One commentator puts it as $31 \%$ for gas and $60 \%$ for oil. ${ }^{26}$ Thus, the success rate in proving additional reserves will be high relative to the current experience with oil. In the past gas was generally found by accident, as part of the search for oil. Now higher prices encourage gas exploration in its own right and there are many areas of the world that have not been explored. Higher prices will also influence the rate of technological advance and development in gas exploitation, which will increase the ratio of reserves that are economically deliverable. Finally, about one-third of the $30 \%$ of current world gas production that is associated with oil is still flared. ${ }^{26}$

In summary, the supply situation in aggregate terms is conducive to more rapid exploitation. The distribution of these supplies is, however, an obstacle in the way of their use, especially within the conventional gas consumption system. Table 1 shows the geographical distribution of reserves and consumption for broad categories of countries. The two distributions differ markedly. The U.S. and Western Europe have accounted for large components of total consumption and have small shares of total reserves. Nonetheless, they have consumed mostly from domestic supplies and imports have come from nearby sources.

Tables 2 and 3 indicate that this has been changing, as imports have risen and come from more distant sources. In the European countries, much of the gas has been imported from the Groningen field and, more recently, from the North Sea. For example, in $1975,77 \%$ of the French imports, $87 \%$ of the FRG imports, and $48 \%$ of the Italian imports came from the Netherlands. ${ }^{27}$ Other sources have been important as well (e.g., the USSR, Algeria, Libya, Indonesia) and their importance has been growing. A rough indication of the shift toward long-distance imports is given by the time series in Table 3. It shows movements in a synthetic variable: the average distance over which gas is transported from its source to the country of consumption, with weights corresponding to the proportions of that country's total gas imports from each different source. $\dagger$ These data indicate a trend towards imports from more distant sources and, consequently, towards more costly imports.

Such trends have, however, taken place in a period of relatively low natural gas prices. Long-term contracts and other institutional aspects of natural gas markets have tended to retard the rate of adjustment of gas prices to changing market conditions. The immediate effect of sharp increases in oil prices is to reduce the natural gas-oil price ratio. But, though adjustment takes place with a lag, it still occurs. In the industrial sector the lag can be quite short, while adjustment in the household sector tends to be slow. $\ddagger$

The factors so far discussed are at the base of concerns over gas supplies. In a number of major consuming countries natural gas has become a more expensive and a less secure source of energy. Consumption in these countries grew rapidly in the 1960's and early 1970 's, and then more slowly, ${ }^{28}$ though market saturation has generally not been reached and conventional gas use will continue to grow. New import contracts are being negotiated. Increases in import prices and an end to the economic recession will induce exploration ad development closer to home. There appears to be much scope for this in regard to Western European gas supplies, particularly since, in the view of some, Western European governments have been unnecessarily conservative in promoting the development of indigenous supplies (P. R. Odell in Ref. 25). The use of incentives to encourage the substitution of natural gas in conventional uses for other fuels could also increase. This has been recommended by the IEA to several of its member countries. ${ }^{30}$

†In principle, this is a fully measurable variable. Here, however, it is very much an approximation. Statistics on domestic production and imports from each country were available. However, tracing gas through an increasingly complex pipeline and tanker distribution system, and even finding consistent data on distances within that system, are very difficult and too costly for the present analysis. Consequently some arbitrary assumptions were made. The distances used were the air kilometers from the capital of the country of origin to a large central city in the consuming country (Paris, Rome, London, and Frankfurt for the countries shown in Table 3). No attempt was made to account for distribution within the consuming country. Domestic gas was assigned a zero distance. The last assumption, plus the locations of gas fields in producing countries relative to the cities considered, imply that the numbers derived understate the true average distance.

$\ddagger$ Data from which such ratios can be computed for four countries are available in Ref. 10, pp. 50-59. 
Table 1. World natural gas reserves and consumption, 1978 (billions of $\mathrm{m}^{3}$ ).

\begin{tabular}{|lrccc|}
\hline Country & Reserves & $\begin{array}{c}\% \text { of } \\
\text { Total }\end{array}$ & $\begin{array}{c}\text { Annual } \\
\text { Consumption }\end{array}$ & $\begin{array}{c}\% \text { of } \\
\text { Total }\end{array}$ \\
\hline U.S. & 5000 & 7.8 & 590 & 40.5 \\
Western Europe & 4000 & 6.3 & 215 & 14.8 \\
Communist countries & 24000 & 37.5 & 465 & 32.0 \\
OPEC countries & 25000 & 39.1 & 55 & 3.8 \\
Others & 6000 & 9.4 & 130 & 8.9 \\
\hline
\end{tabular}

Source: Ref. 26

Table 2. Net imports of natural gas as a percentage of gross consumption.

\begin{tabular}{|r|r|r|r|r|r|r|r|}
\hline Year & FRG & France & Italy & Japan & U.K. & U.S. & $\begin{array}{c}\text { World } \\
\text { Averaget }\end{array}$ \\
\hline & & & & & & & \\
1955 & - & - & - & - & - & -0.2 & 0.5 \\
1960 & - & - & - & - & - & 1.2 & 1.2 \\
1965 & 1.4 & 3.6 & - & - & 98.6 & 2.7 & 2.2 \\
1970 & 22.6 & 34.2 & - & 32.2 & 7.7 & 3.5 & 4.3 \\
1971 & 29.7 & 41.5 & 0.5 & 34.5 & 4.7 & 3.8 & 5.4 \\
1972 & 37.2 & 48.7 & 8.4 & 34.5 & 3.1 & 3.9 & 6.2 \\
1973 & 42.0 & 56.3 & 10.5 & 49.3 & 2.7 & 4.2 & 7.3 \\
1974 & 50.3 & 60.2 & 23.5 & 64.3 & 1.9 & 4.1 & 8.6 \\
1975 & 57.1 & 61.8 & 37.4 & 71.3 & 2.5 & 4.4 & 9.5 \\
1976 & 60.4 & 67.2 & 42.7 & 76.0 & 2.7 & 4.5 & 10.3 \\
1977 & 62.2 & 67.6 & 48.5 & 77.9 & 4.3 & 4.8 & 10.8 \\
1978 & 62.6 & 68.7 & 50.8 & 84.4 & 11.8 & 4.6 & 11.4 \\
1979 & 66.1 & 70.7 & 52.1 & 87.8 & 18.6 & 5.7 & 12.6 \\
1980 & 68.1 & 73.1 & 55.0 & 90.5 & 22.6 & 4.6 & 13.1 \\
\hline
\end{tabular}

International trade in gas as percent of world production. Source: Ref. 28, Ch. 2 and p. 115.

Table 3. Weighted average distances in kilometers over which imported natural gas is transported.

\begin{tabular}{|l|r|r|r|r|}
\hline Year & France & Italy & U.K. & FRG \\
\hline & & & & \\
1955 & 0 & 0 & 0 & 0 \\
1960 & 0 & 0 & 0 & 0 \\
1965 & 48 & 0 & 1608 & 5 \\
1970 & 198 & 0 & 114 & 83 \\
1971 & 216 & 2 & 70 & 109 \\
1972 & 258 & 86 & 46 & 136 \\
1973 & 330 & 106 & 27 & 184 \\
1974 & 357 & 294 & 40 & 277 \\
1975 & 378 & 898 & 43 & 334 \\
1976 & 435 & 1245 & 59 & 368 \\
1977 & 618 & 1685 & 144 & 422 \\
1978 & 667 & 1912 & 222 & 562 \\
1979 & 669 & - &
\end{tabular}

At the same time, natural gas forecasts do not suggest that any overriding obstacles will be encountered in the supply of increased consumption. There are problems to be solved, but the general thrust of most forecasts is to support the contention that the use of natural gas can be expended. For instance, a recent study of gas use in OECD countries by the IEA ${ }^{20}$ concludes that the share of gas in total primary energy use will be relatively constant over the next decade, and could rise or fall in the 1990's. This implies absolute increases in consumption. Assuming healthy economic growth it would require increases in supply in the range of $13-38 \%$ between 1980 and 2000 . A hard prediction that this or one of the other scenarios studied by the IEA will be the most likely to take place is not 
made, reasonably enough. Difficulties over pricing and sécurity of supply are foreseen, but no warning is given that the postulated supply scenarios are unrealistic.

Forecasts of this sort do not explicitly consider the prospects for methanol; its role as fuel is not well enough established to be accounted for in quantitative gas forecasts. If one is willing to speculate on the innovative use of methanol, however, it is safe to argue that insufficient supplies of gas will not be an obstacle. Growth in conventional gas use will be slower than it has been and proven reserves are expected to grow more rapidly. Methanol has an advantage relative to conventional usage when it comes to exploiting remote gas reserves. Thus it need not interfere with the conventional application of reserves that are more accessible to major markets. In short, some space will be open for methanol in the competition between conventional and new uses of natural gas.

\section{CONCLUSIONS}

Methanol has the capacity to play a significant role in substituting for oil based fuels, but the realization of this capacity is not yet imminent. Some limited preparations for a market in methanol fuels are underway. If and when it begins to function, natural gas will be an important feedstock, certainly during a period of transition, but very possibly beyond that as well.

These conclusions are supported in a number of ways. Methanol is now a cost-efficient competitor for gasoline in many countries if it is used in low-ratio blends. Assuming that the current softness of oil prices is a passing phenomenon, it will become competitive for direct use in larger amounts and as a feedstock for the production of gasoline. Pockets of enthusiasm for market development exist and some initial activities directed to that end are proceeding. Feedstocks with which to produce the required methanol are abundant. While coal has the capacity to become a major feedstock, natural gas is already technologically and economically well established. Increases in the stock of known gas reserves will strengthen that position.

Despite these factors, a number of other issues explain why methanol's market penetration is not imminent. Expectations in the private sector are strongly influenced by what is happening right now, and that does not encourage innovation. The pockets of enthusiasm referred to above are mainly in government and academic circles. There is no evidence of a widespread commitment from industrial actors. Some research and other preparations have been undertaken by those concerned with the usage of methanol, but there is little apparent activity on the part of methanol producers. In fact, a conflict of interest in the development of methanol fuel is likely to exist because some gas suppliers are also oil suppliers. This is heightened by the contention in oil circles that gasoline will not be in short supply for a long time. Finally, conventional gas use is still growing. Although there is likely to be gas available to supply both categories of use, this growth is occupying those who exploit gas reserves.

While the existence of these opposing forces makes methanol's fortunes uncertain, it is likely that it will develop into an important fuel. Even if gasoline supplies are expected to be stretched farther than previously forecast, the desire in Western industrialized nations for diversification and security of fuel supply is very strong. Thus, in regard to government policy, short-run weakness in oil markets is not likely to destroy that momentum, though it will slow it down. The limited commitment to methanol fuel development in the private sector is understandable at present. It will increase when the recession ends if there are further attempts by government to strengthen the expectation that alcohol fuels will be used. That would help to eliminate the "chicken-egg" worry that holds back investment in production capacity and infrastructure. Such action will, however, develop only slowly in the normal course of events. If, on the other hand, political events or decisions taken by OPEC create new oil shortages, the impetus for methanol development will be concentrated. The current preparatory activity will allow methanol use to get underway much more rapidly than would have been possible only a few years ago. A worldwide interest in alternative fuels arose because of turmoil in oil markets. The next stage of their development could well come about in the wake of another oil crisis. 


\section{REFERENCES}

1. Committee of Common Market Automobile Constructors, "Methanol as a Fuel Component", Position Paper L/3/80, Square de Meeus, Brussels (1980).

2. E. M. Goodger, Hydrocarbon Fuels. Wiley, New York (1975).

3. T. J. Russell, Alcohols-An Overview of Their Possible Use as Transportation Fuels. The Associated Octel Co. Ltd., Milton Keynes, England (1980).

4. Proceedings, Fifth International Alcohol Fuel Technology Symposium, Auckland. Vols. 1-3. P.O. Box 5098, Wellington, New Zealand (1982).

5. Proc. Fourth Int. Symp. Alcohol Fuels Tech. Guaruja-SP-Brazil, Vols. 1-3 (1980).

6. E. N. Tiratsoo, Natural Gas. Scientific Press Ltd., Beaconsfield, England (1979).

7. Petr. Econ. 49(4), 154 (1982).

8. "Carburols: Le rève se met en marche", Bulletin 4495, 22 Dec., SOCIDOC-BIP (SARL), 142 rue Montmartre, Paris (1981).

9. "Les dispositions du programme français de carburols" and "L'état d'avancement du programme français de carburants de substitutions", Enerpresse Bulletins 2240 (16 Jan.) and 2288 (25 March), SOCIDOC-BIP (SARL) (1981).

10. C. P. Doblin, The Growth of Energy Consumption and Prices in the USA, FRG, France and the U.K. RR-82-18, International Institute for Applied Systems Analysis, Laxenburg, Austria (1982).

11. Oil and Gas J. 80(16), 142 (1982).

12. Chem. Engng 85, (19 May, 1980).

13. Hydrocarbon Process. 58(7), 19 (1979).

14. Ontario Ministry of Energy, Alternative Transportation Fuels for Ontario, Toronto (1981).

15. OPEC, Ann. Statist. Bull. (1979).

16. M. Quinlan, Petr. Econ. 47(10), 434 (1980)

17. Hydrocarbon Process. 60(11), 183 (1981).

18. G. Bonfiglioli and F. Cima, Economics of gas utilization in different fields. Proc. Symp. Ideal Utilization of Natural Gas in the Arab World, Algiers. Organization of Arab Petroleum Exporting Countries, Kuwait (1980).

19. F. Cima, "Economics of Natural Gas Uses", internal paper supplied by the author, Manager, Economic and Feasibility Studies Department, Snamprogetti S.p.A., C.P. 12059, Milan, Italy (1981).

20. IEA, Natural Gas, Prospects to 2000. OECD, Paris (1982).

21. G. C. Humphreys, Energy Technology Handbook (Edited by D. M. Considine), Vol. 2, p. 120. McGraw-Hill, New York (1977).

22. P. T. Dubetz and S. S. Marsden, Oil and Gas J. 79(4), 124 (1981)

23. P. T. Dubetz, The Transportation of Prudhoe Bay Gas 10 Market: A Comparison of Methods. M. A. Thesis, Stanford University (1981).

24. E. A. Symons and A. I. Miller, Gasoline and Other Transportation Fuels from Natural Gas in Canada. Atomic Energy Canada Ltd., Chalk River, Ontario (1981).

25. Proc. IIASA Conf. Conventional and Unconventional World Natural Gas Resources. International Institute for Applied Systems Analysis, Laxenburg, Austria (1980).

26. N. Ait-Laoussine, In World Energy: Issues and Policies (Edited by R. Mabro). Oxford University Press, Oxford (1980).

27. U.N., Ann. Bull. Gas Statistics. (various years)

28. M. Valais, P. Boisserpe and J. L. Gaden, The World Gas Industry. Editions Technip, Paris (1982)

29. World Airways Guide, Part One. ABC Travel Guides Ltd., Dunstable, U.K. (1982).

30. IEA, Energy Policies and Programmes of IEA Countries. OECD, Paris (1980). 